\title{
(2) OPEN ACCESS \\ BLANKETS: a toasty tool to improve social history documentation for our older patients
}

\author{
Bronwen E Warner (D) ,',2 Kate Millar, ${ }^{1,2}$ Mhairi Bolland, ${ }^{1}$ Jackie McNicholas, ${ }^{1}$ \\ Melanie Dani ${ }^{1,2,3}$
}

Internal medicine, Imperial College Healthcare NHS Trust, London, UK

${ }^{2}$ Imperial College London, London, UK

${ }^{3}$ Cutrale Peri-Operative and Ageing Group, Imperial College London, London, UK

Correspondence to Dr Bronwen E Warner, Imperia College Healthcare NHS Trust, London W2 1NY, UK:

b.warner@imperial.ac.uk

Received 30 March 2021 Accepted 17 June 2021

Check for updates

(c) Author(s) (or their employer(s)) 2021. Re-use permitted under CC BY-NC. No commercial re-use. See rights and permissions. Published by BMJ.

To cite: Warner $\mathrm{BE}$, Millar $\mathrm{K}$, Bolland $\mathrm{M}$, et al.

Postgrad Med J Epub ahead of print: [please include Day Month Year]. doi:10.1136/

postgradmedj-2021-140207

\begin{abstract}
A thorough social history is an important component of all medical clerkings and is particularly crucial when admitting an older patient. Standards exist to guide the social history content but are rarely referenced in practice. This quality improvement project conceived and implemented the novel BLANKETS (Bladder and bowels, Legal arrangements, Activities of daily living, Neurology (cognition), Kit (dentures, hearing or visual aids), EtOH and smoking, Trips, walking aids and exercise tolerance, Setup at home) tool for social history documentation, derived from existing standards, at a specialist medical inpatient hospital setting. Over a 15week period with two cycles of intervention involving 125 patients in total, there was good staff engagement and overall improvement in social history documentation with 194/403 (48.1\%) vs 199/545 (36.5\%) criteria met overall and on average $6.3 / 13$ vs $4.7 / 13$ criteria documented for each patient. The social history BLANKETS tool is a memorable acronym to prompt clerking doctors to take a thorough and focused social history which is intrinsic to determining appropriate rehabilitation goals for effective discharge planning and setting appropriate ceiling of care decisions.
\end{abstract}

\section{BACKGROUND}

A thorough social history is an important component of all medical clerkings and is particularly crucial when admitting an older patient. A detailed social history provides key information required to assess accurately an elderly patient's frailty status, ${ }^{1}$ a measure which helps to determine the patient's probable outcome ${ }^{2}$ and thus helps to anticipate their needs. Knowing a patient's usual 'set-up' is necessary for the multidisciplinary team (MDT) to gauge rehabilitation goals and targets for discharge and can help decide whether a new home environment or change in the 'package of care' is needed. Recording risk factors for medical conditions such as alcohol misuse and smoking contributes to the differential diagnosis and introduces an opportunity to counsel towards healthy behaviours. Of particular prominence in the COVID-19 era, understanding a patient's baseline functioning can guide decision-making around ceilings of care, leading to timely escalation or appropriate limitations. ${ }^{3}$

The British population is ageing and medical and surgical subspecialties must adapt their practices and admissions processes accordingly. This quality improvement project (QIP) was carried out on renal inpatient wards in a London tertiary centre which has a predominance of older, frail patients, often with multiple comorbidities and therefore requires a thorough approach to social history taking and documentation to guide patient management and to optimise patient experience and outcomes.

We aimed to improve social history taking and documentation within the renal department through the creation and implementation of the BLANKETS (Bladder and bowels, Legal arrangements, Activities of daily living, Neurology (cognition), Kit (dentures, hearing or visual aids), $\mathrm{EtOH}$ and smoking, Trips, walking aids and exercise tolerance, Setup at home) tool.

\section{METHODS}

The environment is two renal inpatient wards within a specialist tertiary referral centre hospital setting which uses electronic records. All admitted patients aged $\geq 65$ years were included. The QIP used 'plan, do, study, act' methodology over 15 weeks with a minimum of 1 month from each intervention to reaudit and was conducted by three internal medicine training trainees with the support of a geriatric consultant and frailty clinical nurse specialist and the endorsement of the specialty service.

Standards for the social history were derived from the Academy of Medical Royal Colleges 'Standards for the Clinical Structure and Content of Records' for all medical record keeping ${ }^{4}$ and the National Institute for Health Research Applied Research Collaboration West 'Information About $\mathrm{Me}$ ' project focused on social histories for older patients. ${ }^{5}$ These standards were chosen because they have been validated or are accepted in current practice and were felt by the authors to reflect gold standard social history documentation appropriate for the clinical setting. The criteria were as follows: bladder, bowels, legal planning, assistance with activities of daily living, carers, memory problems, hearing aids/glasses/dentures, alcohol, smoking, falls, mobility aids, exercise tolerance and household composition.

The BLANKETS acronym was developed during the QIP and used as a tool for intervention (figure 1). It was conceived using the standards described previously and included all major aspects of these standards. The tool is designed to be an attractive and memorable way of prompting documentation of key social history documentation components. The word 'blankets' was considered a positive term to reflect the value of social histories in enhancing the comfort and care of older patients.

All notes for the first 48 hours of a patient's admission were reviewed as a pragmatic time period by 


\section{Bladder and bowels}

Legal: existing LPA, advanced directive?

ADLs: any carers? what do they need help with?

Neuro: any memory problems?

Kit: do they use dentures, hearing aids, glasses?

EtOH (alcohol) and smoking

Trips/falls, walking aids and exercise tolerance

Setup at home: who do they live with? what sort of accommodation?

Figure 1 The BLANKETS tool for social history documentation.

which it was felt key social history information should have been obtained from the patient or in a collateral history. Documentation from all staff groups was included, reflecting the role of the MDT in assessing a patient's baseline function and recognising that in clinical practice every available source of information will be used if there is a question about aspects of the social history. The outcome measure was the number of participants with each criterion documented; process measures were documentation of any social history and junior doctor awareness of the QIP.

With a view to assessing overall performance in social history documentation, the data were analysed in terms of total number of criteria met across the entire cohort $(13$ criteria $\times X$ number of patients). Univariate analysis was performed using the Chisquared test.

This QIP was registered with the Trust Audit Office REN_030.

\section{RESULTS}

\section{Baseline data}

There were 41 patients admitted over a 1-month period. Twentyseven patients $(65.9 \%)$ had some form of information relating to a social history in the admitting doctor's clerking document. No patients had all criteria documented. Overall across the cohort, $199 / 545$ (36.5\%) criteria were met with a mean of 4.7/13 (SD 1.9) criteria for each patient (figure 2).

As data collection proceeded, it was appreciated that different staff groups were responsible for documenting social history and that an effective focused initial intervention would target the group most involved in social history documentation. A subgroup analysis of 19 patients was therefore performed to determine which staff group documented most social history information and therefore could

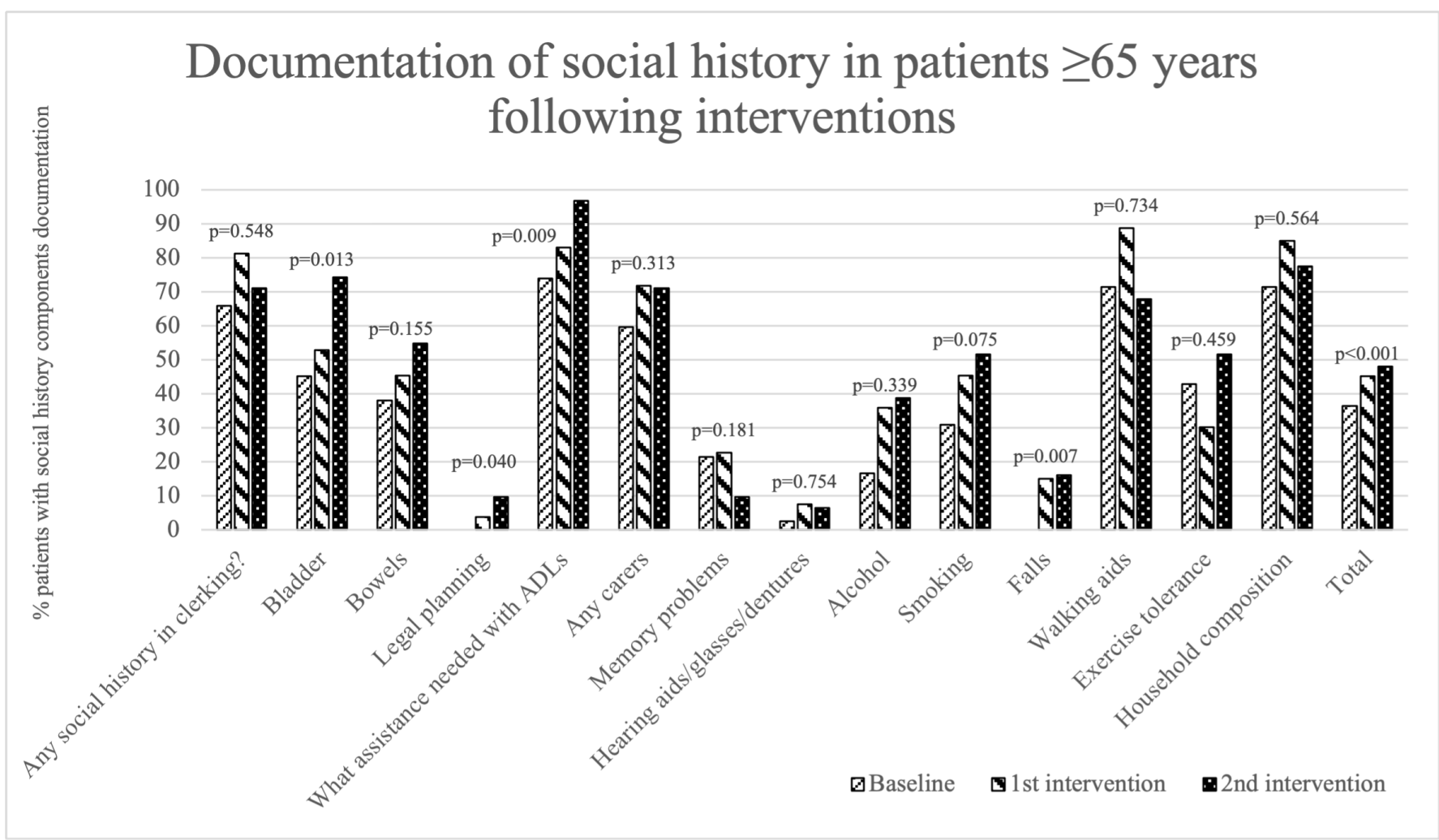

Figure 2 Use of the BLANKETS (Bladder and bowels, Legal arrangements, Activities of daily living, Neurology (cognition), Kit (dentures, hearing or visual aids), EtOH and smoking, Trips, walking aids and exercise tolerance, Setup at home) tool at baseline and following interventions. P values are demonstrated comparing baseline data with after the second intervention. ADLs, activities of daily living. 
first be targeted to improve practice. Doctors documented most history overall (50\%) followed by nurses (37.5\%) and allied health professionals (12.5\%). A decision was therefore made to aim initial interventions at junior doctors.

\section{First intervention}

The BLANKETS acronym was conceived and distributed among junior doctors (doctors who have been working for up to 3 years postqualification) via the WhatsApp messaging platform, Trust email and posters displayed on the wards. The tool was explained in accompanying text. Frequent reminders were posted in the junior doctor WhatsApp group and the junior doctors on the QIP team invited questions and comments from their colleagues in person during daily clinical activities to prompt discussion, awareness and engagement with the QIP.

Repeat data collection from 53 patient notes using the same methods showed improvement across almost all domains (figure 2).

\section{Second intervention}

Using rapid cycle change methodology, a survey was distributed among junior doctors to gauge awareness and perspectives on the QIP and to identify strategies for further intervention. Eleven of 13 junior doctors responded. All responders reported that they were aware of the QIP and 10/11 felt that there was room for improvement in the management of older patients on the wards. The most common reason for not changing practice was being unable to recall what should be included. Nine of the 11 responders said that a lanyard card with a reminder of the guidelines would be helpful.

Lanyards were designed with a reminder of the BLANKETs tool and distributed among all junior doctors.

At the final data collection of 31 patients, 22/31 (71\%) patients had a social history in the initial clerking. Overall across all 13 criteria, 194/403 (48.1\%) vs 199/545 (36.5\%) (p<0.001) criteria were met with a mean of 6.3 (SD 2.5) criteria for each patient (figure 2).

\section{DISCUSSION}

This QIP demonstrates the use of the BLANKETS tool to improve social history documentation in medical patients aged $\geq 65$ years at a specialist centre.

There are several barriers to documenting a thorough social history. In a busy hospital setting, time pressures may prompt juniors to deprioritise social history in favour of more immediate tasks. At this centre, a high proportion of the patient cohort do not speak English or speak limited English, meaning that additional sources of information or translation services must be employed, all of which are invaluable but take time and effort. As demonstrated here by the junior doctor survey, staff may not be fully aware of all of the components of a gold-standard social history.

The COVID-19 pandemic has shown us that the perfect storm of unstable patients who may or may not benefit from escalation in the context of pressured services makes it essential to understand a patient's baseline in order to decide appropriate ceilings of care. The decision to escalate care is based on the immediate clinical problem but also on whether a patient may be expected to survive or benefit from more invasive therapy. The social history is a key tool in gathering information necessary to decide on ceiling of care, and while conducting this QIP, it was clear that if the opportunity is not taken while clerking, it may be lost.
Main messages

- The BLANKETS tool is a memorable acronym which we have demonstrated can be used to prompt clerking doctors to take a more thorough and focused social history from older patients in the medical inpatient setting.

\section{Strengths}

Through the BLANKETS tool, we have created an understandable and memorable structure, based on national standards, which can be widely applied to any inpatient admission process. The tool does not produce an entirely comprehensive social history as this would be impractical in the acute admissions setting, but is thorough enough to highlight any patient issues that may require further MDT input and to better anticipate patient needs and outcomes. The QIP is patient-focused, aiming to improve social history documentation with a view to gauging rehabilitation goals, identifying health risk factors and setting appropriate ceilings of care.

\section{Weaknesses}

Although an overall improvement was seen in social history documentation, this effect was not consistent across every domain, and there remains a need to focus on areas done less well, in particular records of legal frameworks such as existing 'do not attempt resuscitation' agreements and concerns regarding cognitive impairment and falls. Documentation by junior doctors of walking aids and use of equipment such as hearing aids did not show significant improvement, perhaps because these domains are often focused on more by other members of the MDT such as occupational therapists. However, this QIP clearly defines performance in different domains of the social history and therefore gives direction on which aspects could be improved using an MDT approach.

This QIP analysed the social history documentation within the first 48 hours of the inpatient admission. During this time, the patient is likely to be at their most unwell or unstable, which might hinder the ability to obtain a thorough social history and means that the MDT focus is elsewhere as they provide lifesaving care. It is recognised that the BLANKETS tool could increase the time taken to complete the clerking and therefore detain junior doctors from completing other tasks, reflecting the importance of recognising unintended outcomes and balancing positive and negative implications of quality improvement in the shorter term. Although effects of the BLANKET tool were only measured in the first 48 hours, it could also be implemented by clinicians or the wider MDT later in the patient's admission once they are more stable.

\section{In the future}

The department plans to continue the use of BLANKETS in the admissions process and is looking to expand its scope to the outpatient setting.

\section{CONCLUSION}

The social history BLANKETS tool is a memorable acronym to prompt clerking doctors to take a thorough and focused social history, which in turn contributes to effective discharge planning and appropriate ceiling of care decisions. 


\section{Current research question}

How can we improve social history documentation in older medical inpatients?

Contributors BEW undertook data collection and analysis, drafted the initial article and reviewed the final article prior to submission. KM undertook data collection, was involved in article drafting, performed statistical analysis and reviewed the final article prior to submission. MB undertook data collection and reviewed the final article prior to submission. JMcN provided project supervision and reviewed the final article prior to submission. MD provided project supervision, was involved in article drafting and reviewed the final article prior to submission.

Funding The authors have not declared a specific grant for this research from any funding agency in the public, commercial or not-for-profit sectors.

Competing interests None declared.

Patient consent for publication Not required.

Provenance and peer review Not commissioned; externally peer reviewed.

Data availability statement Data are available upon request
Open access This is an open access article distributed in accordance with the Creative Commons Attribution Non Commercial (CC BY-NC 4.0) license, which permits others to distribute, remix, adapt, build upon this work non-commercially, and license their derivative works on different terms, provided the original work is properly cited, appropriate credit is given, any changes made indicated, and the use is non-commercial. See: http://creativecommons.org/licenses/by-nc/4.0/.

\section{ORCID iD}

Bronwen E Warner http://orcid.org/0000-0003-1897-4682

\section{REFERENCES}

1 Rockwood K, Song X, MacKnight C, et al. A global clinical measure of fitness and frailty in elderly people. CMAJ 2005;173:489-95.

2 Clegg A, Young J, lliffe S, et al. Frailty in elderly people. The Lancet 2013;381:752-62.

3 National Institute for Health and Care Excellence. COVID-19 rapid guideline: managing COVID-19 2021.

4 Academy of Medical Royal Colleges. Standards for the clinical structure and content of patient records 2013

5 National Institute for Health Research Applied Research Collaboration West. Information about me, 2020. Available: https://arc-w.nihr.ac.uk/ [Accessed 20 Jun 2021]. 